\title{
A língua absolvida: as palavras das crianças nas aulas de ciências
}

\author{
The absolved language: children's words in science classes
}

\author{
Sheila Alves Almeida' \\ Orlando Gomes Aguiar Junior ${ }^{2}$ \\ Maria Emília Caixeta de Castro Lima²
}

\begin{abstract}
'Universidade Federal de Ouro Preto (UFOP), Departamento de Biodiversidade, Evolução e Meio Ambiente, Ouro Preto, MG, Brasil. Autora correspondente: sheilaalvez@ufop.edu.br

²Universidade Federal de Minas Gerais (UFMG), Faculdade de Educação, Departamento de Métodos, e Técnicas de Ensino, Belo Horizonte, MG, Brasil
\end{abstract}

Resumo: Este trabalho tem como objetivo compreender as interações discursivas produzidas pelas crianças em uma aula de Ciências, sem a intervenção da professora, em uma situação de trabalho em grupo. Para tanto, foi analisado um episódio de uma aula em que quatro crianças respondem a questões de um questionário sobre o processo de fermentação. A metodologia escolhida tem como pressuposto a tese de que os sujeitos aprendem na interação com o outro, mediados pela linguagem. Os dados foram analisados a partir de categorias propostas por Mercer e Littleton acerca da aprendizagem colaborativa, em trabalho desenvolvido em aulas de ciências em uma classe de terceiro ano do Ensino Fundamental de uma escola pública. No corpus analisado, a conversa exploratória se manifesta, sobretudo, nas interações entre professora e crianças nas aulas, durante a abertura de um novo tema.

Palavras-chave: Ensino fundamental; Ensino de ciências; Trabalho em equipe; Atividades de grupo; Aprendizagem colaborativa.

Abstract: This paper aims to explain the discursive interactions produced by children in a science class, without the intervention of the teacher, in a groupwork situation. To this end, an episode of a class was analyzed in which four children answer questions in a questionnaire about the fermentation process. The chosen methodology assumes that subjects learn in the interaction with each other, a process that is mediated by language. Data were analyzed using categories proposed by Mercer and Littleton about collaborative learning, in a study carried out in science classes in a third-year elementary class in a public school. In the analyzed corpus, the exploratory conversation is manifested, above all, in the interactions between the teacher and the children in the classes to open a new topic.

Keywords: Elementary school; Science teaching; Team work; Group activities; Collaborative learning.

Recebido em: $02 / 11 / 2020$

Aprovado em: 10/05/2021 
[...] Entre palavras e combinações de palavras circulamos, vivemos, morremos, e palavras somos $[\ldots]$

Carlos Drummond de Andrade (ANDRADE, 1988, p. 1.795).

\section{Introdução}

Em seu livro A língua absolvida, Elias Canetti (CANETTI, 1987), ao relatar suas memórias, descreve o seu processo de conhecimento do mundo pela linguagem e as dificuldades, muitas vezes enfrentadas, para liberar a sua voz. Destaca um episódio de sua infância, qual seja, uma ameaça de corte de sua língua por um canivete para mantêlo calado. Em seu texto, mostra como foi prisioneiro da língua, como ficou remoendo esse fato por muitos anos até decidir contá-lo à mãe, percebendo, então, seu significado. A obra de Canetti evidencia a interdição do discurso, a possibilidade de falar e de se realizar por meio da língua. A leitura desse livro nos inspira a pensar sobre o modo como as palavras circulam nos diferentes ambientes da vida, especialmente na escola, espaço que tem como um dos objetivos o ensino da linguagem oral em espaços formais. Contudo, geralmente, o trabalho com a oralidade na escola é limitado a atividades como leitura em voz alta e discussões que não têm por objetivo propiciar o desenvolvimento da competência comunicativa dos alunos (GOULART, 2005). Muitas vezes, o diálogo entre crianças na sala de aula é desencorajado, pois, cria dispersão e situações que, supostamente, fogem ao controle da professora. Mesmo em práticas pedagógicas que enfatizam a autonomia das crianças, o significado do diálogo em grupo tende a ser menosprezado em favor da ação individual (MERCER; LITTLETON, 2007). Assinalam os autores (2007) que o diálogo aluno-aluno é visto como desconfortável por muitos professores por temerem que sua competência seja julgada se não conseguirem manter a classe em silêncio. Assim, embora a experiência da vida cotidiana mostre o valor do diálogo, a prática educacional conspira implicitamente contra ele. Desta maneira, é importante destacar o incômodo que a interação aluno-aluno causa em alguns docentes por julgarem que essa seria uma perda de tempo, que atrasaria o ensino do conteúdo, na medida em que as crianças falam qualquer coisa, pois ainda não aprenderam sobre o assunto. Por último, mas não menos importante, para muitos professores, aulas em que as crianças são livres para falar coloca em risco a aprendizado dos conceitos corretos e concorrem para o surgimento de questões que colocariam o professor em dificuldade para responder.

Na prática cotidiana da sala de aula, as conversas das crianças ocorrem em todo o tempo da aula mas, em geral, não giram em torno das atividades escolares. Embora elas conversem enquanto trabalham, muitas vezes, as atividades não incentivam a discussão ou exigem que elas conversem sobre as tarefas propostas (MERCER; LITTLETON 2007).

Observa-se, nas aulas de Ciências, que as crianças gostam de comentar suas observações, fazem perguntas baseadas nas experiências cotidianas que, na maioria das vezes, impressionam os adultos pela lógica do raciocínio ou pela aparente falta dela aos olhos das professoras. Aliás, antes mesmo de frequentarem a escola, as crianças buscam explicações para o que veem, ouvem e sentem. O discurso infantil sobre coisas do mundo expressa o desejo de compreender o mundo e de produzir as mais diferentes formas de questionamentos sobre a experiência com as coisas e as pessoas. 
Assim sendo, é importante que esse repertório de representações e explicações tenha lugar de manifestação das crianças garantido em sala de aula, pois se constituem como fator relevante no processo de aprendizagem. A escuta atenta do professor é porta de entrada para que se estabeleçam diálogos com temas e ideias científicas a serem vivenciados pelas crianças no enfrentamento de desafios e problemas. Cabe assinalar que, um número crescente de pesquisadores tem investido em tentativas de ampliar o conhecimento sobre a linguagem das crianças nas aulas de Ciências (ALMEIDA, 2011, 2018; ALMEIDA; GIORDAN, 2012; BOSCO, 2015; CANDELA, 1999; CAPECCHI; CARVALHO, 2000; TEIXEIRA, 2009). Em seus estudos sobre a linguagem, Mercer e Hodgkinson (2008) indicam que conversa em sala de aula, pela qual as crianças dão sentido e significado aos conceitos científicos, tem sido objeto de pesquisa educacional há mais de 40 anos.

No Brasil, Almeida (2018), inspirada em Vygotsky, salienta a importância da produção de textos orais pelas crianças nas aulas de ciências. Para a autora, esse processo permite que elas reconheçam diferentes e/ou novos significados para as palavras. Kripka et al. (2017) também defendem a importância de um ambiente dialógico para a construção dos conceitos científicos no ambiente escolar.

Face à magnitude dos estudos sobre a linguagem nas aulas de Ciências, torna-se urgente a produção de conhecimentos que possam orientar práticas e investigações sobre as interações discursivas em situações em que as crianças trabalham em grupo sem intervenção da professora. Nessa vertente, das várias alternativas de análise das interações orais que uma aula de Ciências comporta, as questões de investigação aqui ressaltadas são: como um grupo de crianças responde a um questionário sobre um conceito científico não estudado na sala de aula? Que sentidos elas constroem para as perguntas? Quais são os modos de interação verbal das crianças em um contexto em que são levadas a pensar juntas?

Para tal, foi selecionado um episódio de sala de aula em que quatro crianças respondem a um questionário apresentado pela professora. Analisa-se, aqui, o sentido que as crianças dão às perguntas em suas produções orais, o que remete a construção social do discurso, questões necessárias para a construção do conhecimento científico. Assim, o que ecoa neste trabalho são as vozes das crianças, a oralidade entendida como atividade verbal importante, presente em situações em que as crianças produzem discursos em colaboração.

\section{Referenciais teóricos}

Em seus estudos sobre a psicogênese, Piaget (1970) refutou a ideia da transmissão de conhecimentos de adulto para criança como modelo para o desenvolvimento cognitivo. Para Piaget (1994), a interação das crianças com os adultos era vista como irrelevante, e, em alguns casos, como prejudicial, pois interferiria na exploração das crianças de seu ambiente físico e, portanto, na construção ativa do seu conhecimento. De acordo com o epistemólogo, a fala dos adultos na interação com as crianças:

[...] se alía constantemente con el egocentrismo infantil: precisamente porque el niño no puede establecer un contacto realmente mutuo entre él y el adulto que permanece encerrado en su yo. Por una parte, el niño tiene una ilusión demasiado pronta de acuerdo; mientras que en realidad sólo sigue su propia fantasía. Por otra parte el adulto abusa de su situación en lugar de buscar la igualdad. Por lo que respecta a las reglas morales, el niño se somete más o menos completamente, en intención, 
a las reglas prescritas, pero éstas, al ser en cierto modo ajenas a la conciencia del sujeto, no transforman verdaderamente su conducta. Por ello el niño considera la regla como sagrada, a pesar de no practicarla realmente. (PIAGET, 1984, p. 50).

Piaget (1994) considerava a interação entre crianças uma fonte particularmente poderosa de progresso. Para o autor, a incapacidade das crianças de avaliarem diferentes pontos de vista ou variáveis de um problema, em razão do egocentrismo, é o maior obstáculo à realização do chamado pensamento operacional. Segundo Piaget (1994), quando confrontadas com um problema a ser resolvido, as crianças geralmente se fixam no primeiro fator relevante que identificam e ignoram outros possíveis. 0 progresso na compreensão se dá quando a criança se depara com algo que perturba essa centralização. Uma das fontes para esta perturbação é a exposição a alguém que vê as coisas de maneira diferente, em uma situação que exige o confronto de respostas conflitantes. Contudo, Piaget (1994) considerou que os adultos, pelo poder e status que apresentam às crianças, não propiciam uma situação de aprendizagem porque ele considerava pouco provável que elas externassem pensamentos genuínos aos adultos. No caso de exposição a um ponto de vista diferente, no contexto de uma interação com outra criança, no entanto, a dinâmica social mais igualitária da situação criaria uma pressão para a resolução das diferenças. Segundo o autor, "[...] a crítica nasce da discussão e a discussão só é possível entre iguais [...]" (1994, p. 409) Em outro texto, ele afirma:

[...] esta sumisión de los pequeños a los mayores no conduce a una cooperación en la acción: produce simplemente una especie de mística, de sentimiento difuso de participación colectiva que, como muchas místicas, va unido al egocentrismo. Efectivamente, veremos que la cooperación entre iguales no sólo cambiará poco a poco la actitud práctica del niño sino que además, cosa esencial, hará desaparecer esta mística de la autoridad. (PIAGET, 1984, p. 51).

Assim, de acordo com Piaget (1994), o início do progresso intelectual é visto no conflito de perspectivas entre pares. Para esse autor, o conflito de ideias e a necessidade de resolver um problema levam as crianças a reexaminar suas ideias iniciais.

Partindo de outros pressupostos, Vygotsky (1993) propôs que a construção de conhecimento e compreensão é uma atividade inerentemente social. Para esse autor, a interação das crianças com artefatos sociais a elas disponibilizados, com a mediação de outro sujeito, é que possibilita a apropriação de conhecimentos. Para esse autor, o desenvolvimento cognitivo das crianças ocorre sob a tutela de adultos, pelo qual essas 'ferramentas culturais' se tornam parte integrante dos próprios recursos mentais da criança: um processo de internalização do conhecimento adquirido. Assim como Piaget (1994), a interação entre pares é sinalizada por Vygotsky (1993) como tendo um papel potencialmente importante no aprendizado e desenvolvimento. Mas, enquanto a ênfase de Piaget (1994) está nas interações entre crianças de níveis semelhantes de desenvolvimento, a ênfase de Vygotsky (1993) está nas interações entre os que têm mais e menos conhecimento.

De acordo com Vygotsky (1993), os processos de interação entre a criança e os outros tornam-se a base para o desenvolvimento psicológico. O aprendizado e o desenvolvimento são vistos como processos interpessoais e intrapessoais, mediados por ferramentas culturais: a mente surge no curso da atividade conjunta. 
A teoria de Vygotsky (1993) nos ensina que o processo de aprendizagem resulta de uma interação entre sujeitos em uma dada cultura: é através dos 'outros' e da linguagem que nós humanos estabelecemos relações com os objetos de conhecimento. Então, a atividade do sujeito, longe de ser vista como ação de um indivíduo isolado, é percebida na interação, sendo sempre mediada pelos signos linguísticos. Estes são construídos cultural e historicamente também nas interações sociais sejam eles vocalizados ou não. Assim, a língua, longe de ser neutra, apresenta dialogicidade, usos estratégicos, funções interacionais, envolvimento, negociação, situacionalidade, coerência e dinamicidade.

Com base nessa perspectiva, mas valendo-se de outros conceitos, Bakhtin (1997, p. 36) afirma que "[...] a palavra é o modo mais puro e sensível de relação social". Para esse autor, compreender o universo da palavra não é tarefa simples. É preciso pensar na amplitude de seu significado, em sua relação com outras palavras, na sua invenção, na relação que ela estabelece entre quem a produz e o interlocutor, e nas condições nas quais ela é produzida.

Bakhtin destaca, em toda a sua obra, a importância da interação verbal e seu caráter dialógico. Disso resulta a abordagem histórica e viva da língua e o tratamento sociológico das enunciações. Para ele:

Toda palavra comporta duas faces; é determinada pelo fato de se dirigir a alguém e proceder de alguém. Ela constitui justamente o produto da interação do locutor e do ouvinte e serve de expressão de um em relação ao outro. Através da palavra, defino-me em relação ao outro, isto é, em última análise, em relação à coletividade. A palavra é o território comum do locutor e do interlocutor (BAKHTIN, 1997, p. 113).

Nos estudos de Bakhtin (1997, p. 124), a língua é vista como um fenômeno social, histórico e ideológico, por consequência, "[...] a comunicação verbal não poderá jamais ser compreendida e explicada fora desse vínculo com a situação concreta". O significado se constrói dentro de um determinado discurso e essa construção se dá com o envolvimento dos participantes, da situação imediata ou do contexto mais amplo, ou seja, "[...] a confrontação das mais diferentes refrações sociais expressas em enunciados de qualquer tipo e tamanho postos em relação" (FARACO, 2003, p. 60).

Conforme Bakhtin (1997), a compreensão se dá no confronto dos sentidos que só se realiza no processo de formação de uma réplica, de uma atitude ativa e responsiva. Na construção dessa réplica, novos sentidos são construídos. Na perspectiva bakhtiniana, esse caráter responsivo se vincula à própria compreensão, que é tomada como um processo ativo no qual a resposta é um elemento sempre presente.

Inspirando-se na teoria sociocultural, Mercer (1995) destaca que a experiência do sujeito passa a ganhar um novo sentido quando compartilhada por meio da linguagem porque tanto uma como a outra se modificam em seu uso. Esse autor enfatiza, ainda, que não aprendemos as palavras do dicionário, mas sim por meio da fala dos outros.

Em seus estudos sobre a linguagem, Mercer e Hodgkinson (2008) argumentam que a conversa em sala de aula não é meramente um canal para compartilhar informações ou meio de controle das ideias das crianças; é a ferramenta educacional mais importante para compreender o conhecimento em construção.

Por sua vez, Mercer e Littleton (2007) afirmam que o curso do desenvolvimento cognitivo de qualquer criança dependerá de sua contribuição individual para o processo 
dialógico de desenvolvimento e daqueles com quem interage. De acordo com esses autores, por meio do diálogo, as crianças se apropriam da cultura de sua comunidade e da sociedade. Nesse caso, as ações que as crianças realizam através da conversa incluem: compartilhar informações, instruir, argumentar, narrar, obter informações, avaliar conhecimentos, demonstrar compreensão e avaliar a compreensão.

De acordo com Mercer e Littleton (2007) é por meio da palavra que as crianças podem se envolver em uma aprendizagem colaborativa. Segundo esses autores, aprendizagem colaborativa é aquela em que os participantes se envolvem em uma tentativa coordenada e contínua de pensar juntos, resolver um problema ou, de alguma outra maneira, construir conhecimento comum. Consideram que a colaboração envolve um compromisso conjunto, coordenado com um objetivo de reciprocidade, mutualidade e (re) negociação contínua de significado.

Em relação aos modos pelos quais uma conversa pode se estabelecer, Mercer e Littleton (2007) construíram três categorias de discursos, assim denominadas: conversa competitiva, acumulativa e exploratória.

De acordo com Mercer e Littleton (2007), conversas competitivas raramente são associadas a processos de análise conjunta e construção de conhecimento. Embora possam ocorrer muitas interações entre crianças, o raciocínio envolvido é principalmente individualizado. Além disso, o tipo de relacionamento comunicativo desenvolvido por meio de disputas é defensivo e excessivamente competitivo, e apresenta informações e ideias exibidas ou retidas em vez de compartilhadas. É comum que esse tipo de conversa compreenda padrões de afirmação e comentários de julgamento. Convém esclarecer que, em uma conversa competitiva, pode haver explicitação de diferenças e controvérsias no grupo e que esta pode ser motor para desenvolvimento de ideias, argumentos e raciocínios.

Conforme Mercer e Littleton (2007), em contraste com a conversa competitiva, no discurso acumulativo, as ideias e informações são compartilhadas e são tomadas decisões conjuntas: mas há pouco em termos de desafio ou conflito construtivo de ideias no processo de construção do conhecimento. A conversa acumulativa representa uma conversa que parece centrar mais em preocupações implícitas com solidariedade e confiança, daí o retorno a uma constante repetição e confirmação das ideias e propostas dos parceiros.

Destacam os autores supracitados que a linguagem da conversa exploratória representa uma forma conjunta e coordenada de raciocínio em que os falantes compartilham conhecimento, desafiam ideias, avaliam evidências e consideram opções de maneira lógica e equitativa. As crianças apresentam suas ideias da forma mais clara e explícita necessária para que sejam compartilhadas, analisadas e avaliadas em conjunto. As possíveis explicações são comparadas e as decisões conjuntas são alcançadas. A conversa exploratória exige que as opiniões de todos os participantes do diálogo sejam consideradas; que as propostas sejam explicitamente declaradas e avaliadas; e que o acordo explícito anteceda decisões e ações. Destina-se à obtenção de consenso. A conversa exploratória, ao incorporar perspectivas conflitantes e o compartilhamento aberto de ideias, representa a busca mais visível de consenso por meio de conversas. Trata-se de uma situação de discurso em que todos são livres para expressar seus pontos de vista e os pontos de vista mais razoáveis ganham aceitação. 
Considerando que a linguagem está relacionada ao poder de persuasão, na conversa acumulativa, os sujeitos não disputam pelo controle, enquanto na conversa competitiva, eles o fazem. Por sua vez, na conversa exploratória, o poder circula porque a palavra está em constante negociação. Mercer e Littleton (2007) destacam que as conversas reais são complexas e que essas categorias não codificam de forma clara e separada, qualquer conversa observada. As categorias servem apenas como indicadores de formas de interação verbal. Isso posto, acredita-se que a categorização construída pelos autores é uma ferramenta valiosa para compreender a construção conjunta das respostas das crianças a um questionário.

\section{Metodologia}

Para realizar este estudo buscou-se, em uma escola da Rede Municipal de Belo Horizonte, compreender as diferentes situações de circulação da palavra, e como as crianças produzem enunciações por meio das quais expressam sentidos e significados nas aulas de ciências. A turma investigada era constituída por crianças na faixa etária entre oito e nove anos $-3^{\circ}$ ano do Ensino Fundamental. A professora dessa turma atuava nas séries iniciais há quatro anos e havia se formado em Pedagogia há menos de dez anos. Ela e todos os responsáveis pelas crianças assinaram termo de consentimento livre e esclarecido para participar da pesquisa. Foram descritos os procedimentos de registro e a não identificação dos sujeitos de pesquisa quando da publicação dos resultados. O episódio extraído dessa aula compõe parte dos dados não analisados da tese de (ALMEIDA, 2011).

No que concerne ao trabalho com os eventos de sala de aula, optou-se pela análise microgenética (GÓES, 2000), dada a sua vinculação com a matriz sociocultural, resultando em um relato minucioso dos acontecimentos. Para tanto, os procedimentos metodológicos incluíram registros em vídeo, notas de campo e gravações em áudio de reuniões com a professora, além de textos produzidos pelas crianças. A metodologia escolhida tem como pressuposto as teses de Bakhtin (1997) e Vygotsky (1993), ou seja, os sujeitos aprendem na interação com o outro, mediados pela linguagem. São essas interações que devem ser investigadas ao se examinar o curso de ação do sujeito.

Durante três meses foram observadas as aulas de Ciências em uma das turmas que a referida professora atuava. O acervo da pesquisa corresponde a 18 horas de filmagens ordenadas por data. Com efeito, foi possível construir um cronograma fixo para as filmagens: às terças-feiras na última aula, e às quintas-feiras nos dois primeiros horários. Após cada filmagem, seguiam-se os seguintes procedimentos: assistir às fitas repetidas vezes, com o objetivo de observar as interações discursivas das crianças e da professora na aula de Ciências. Esse minucioso exame das aulas evidenciou que, em uma delas, evidenciou que, em uma delas, após uma conversa preliminar sobre receitas de pães caseiros, a professora solicitou às crianças que respondessem a um questionário sobre a ação do fermento. Em todos os grupos, foi colocado um microfone de lapela em um aluno, sendo o áudio controlado por uma mesa de som. Todos os grupos se empenharam na realização da tarefa, mas um grupo pareceu mais engajado na realização da atividade. O diálogo das crianças desse grupo foi gravado e a transcrição do áudio foi escolhida por apresentar singularidades na linguagem. No grupo escolhido para a investigação, a construção de respostas mais colaborativas foi 
mais evidente. Nos outros grupos, verificou-se que era sempre uma criança com mais iniciativa que respondia todas as questões.

Assim, pretende-se, na análise do episódio selecionado, explicitar os modos de participação das crianças na atividade proposta, em um contexto em que o grupo é levado a elaborar respostas a um questionário.

A seguir, apresenta-se um evento de uma aula de Ciências em que um grupo de crianças responde a um questionário. Esse evento foi dividido em três sequências discursivas. A transcrição dos episódios privilegia a trama das interações dos sujeitos que se expressam oralmente sobre um questionário. A transcrição é constituída de 88 turnos de fala. A primeira sequência - turno 1 a 17 - mostra as crianças tentando cumprir a demanda planejada pela professora e uma conversa acumulativa. Na sequência 2 turno 18 a 51 - o foco discursivo é o trabalho de compreensão do significado das palavras e a continuidade de uma dinâmica discursiva, com características de uma conversa acumulativa entre as crianças. A sequência 3 - turno 52 a 88 - é marcada pela presença de interações discursivas típicas de conversas acumulativas, competitivas e exploratórias.

\section{Resultados e análises}

Após o ritual de entrada, a professora conversou com os alunos sobre alguns procedimentos para empréstimos de livros na biblioteca, em seguida, escreveu a data da aula no quadro e quis saber sobre o para casa da aula anterior, que solicitava a cópia de receitas de pães, com auxílio dos pais ou responsáveis. Todos os alunos levantaram a mão indicando a realização da tarefa e o desejo de ler as receitas de pão. Várias crianças exibiram suas receitas, demonstrando a euforia que a atividade gerara mobilizando mães e avós. Os alunos leram suas receitas, a pedido da professora, que, em seguida, solicitou à turma que respondesse a um questionário, em grupo, sobre a produção do pão. De acordo com a professora, o questionário tinha como objetivo explicitar os conhecimentos prévios das crianças e mobilizar a atenção delas para o tema que seria desenvolvido nas aulas posteriores. Para as aulas posteriores, ela tinha como propósito discutir as questões do questionário com a turma, produzir pães com as crianças, ler e discutir textos sobre o processo de fermentação.

No fragmento de aula analisado, ela orientou os alunos sobre a organização das mesas e as crianças se agruparam por afinidade. Organizados os grupos, a professora registrou no quadro as seguintes perguntas inspiradas no livro Construindo consciências (CARO et al., 2009):

1. Você conhece este método de colocar a bolinha de massa em um copo d'água para saber a hora que de levar o pão ao forno? O que acha que acontece?

2. Por que é que se amassa a massa do pão?

3. Por que para fazer pães é necessário deixar a massa descansando?

4. Você já tinha ouvido falar na palavra fermento? O que ela significa?

5. Dizem que o fermento é o responsável pelo crescimento das massas. Como você acha que isso acontece?

Em seguida, a professora orientou as crianças a copiarem as perguntas, uma após a outra no caderno, atentando para a organização do registro na página. Recomendou, em seguida, que discutissem as perguntas no grupo. Para isso, um aluno deveria ler cada pergunta em voz alta, o grupo deveria discutir as respostas para, assim, chegar a 
uma resposta final, que seria registrada por todos. O quadro 1 apresenta a transcrição das falas das crianças em grupo.

Quadro 1- Perguntas e respostas das questões 1 e 2

\begin{tabular}{|c|c|c|c|}
\hline $\mathbf{T}$ & Participantes & Discurso & Comentários \\
\hline 1 & Gisela & $\begin{array}{l}\text { número um [...] você conhece este método de colocar a } \\
\text { bolinha de massa em um copo d'água para saber a hora de } \\
\text { levar o pão ao forno? o que acha que acontece? }\end{array}$ & \\
\hline 2 & Rodrigo & não [...] então, coloca aí [...] NÃO & $\begin{array}{l}\text { Duas crianças balançam a cabeça afirmativamente } \\
\text { e cada aluno anota a resposta no caderno }\end{array}$ \\
\hline 3 & Gina & pergunta dois [...] por que é que se amassa a massa do pão? & \\
\hline 4 & Pedro & por que se amassa a massa do pão? & \\
\hline 5 & Rodrigo & é porque $[. .]$. & \\
\hline 6 & Gina & é porque $[. .]$. & \\
\hline 7 & Rodrigo & $\begin{array}{l}\text { ó, cada um responde primeiro aí a gente faz votação pra } \\
\text { ver qual é a melhor }\end{array}$ & \\
\hline 8 & Gina & tem que fazer a votação & \\
\hline 9 & Gisela & por que se amassa $[\ldots .]$. & Lê a pergunta com a mão na cabeça \\
\hline 10 & Rodrigo & $\begin{array}{l}\text { porque se amassa [...] para a massa ficar bem dura, fraga? } \\
\text { misturar a massa }\end{array}$ & \\
\hline 11 & Gisela & para a massa ficar bem macia & \\
\hline 12 & Rodrigo & e você? & Aponta para um colega \\
\hline 13 & Gina & igual ao seu & \\
\hline 14 & Pedro & pra misturar & \\
\hline 15 & Rodrigo & não, o dela está certo Zé [...] para ficar macia [...] & \\
\hline 16 & Gina & massa é com c, né? ah não! massa é com dois esses & $\begin{array}{l}\text { Aluna apresenta dúvidas em relação à ortografia } \\
\text { da palavra }\end{array}$ \\
\hline 17 & Rodrigo & para misturar e a massa do pão ficar bem macia & Alunos copiam no caderno \\
\hline
\end{tabular}

Legenda: [...]: indicação de fala interrompida; ?: interrogação; letras maiúsculas: entoação enfática. Fonte: adaptado de Almeida (2011).

No turno 1, Gisela lê a pergunta e, imediatamente, Rodrigo responde no turno 2 negativamente, sem apresentar sinais de engajamento com a pergunta. Embora a questão "o que você acha que acontece" seja um convite à explicitação de ideias, essa parte da pergunta não é discutida pelo grupo. A resposta de Rodrigo é confirmada no momento em que todos escrevem a resposta sem questionar. Rodrigo repete a palavra "não" e opera com a relação de confiança e poder sobre o grupo através da linguagem. A aceitação sem críticas e confirmação da resposta pelas outras crianças do grupo indica que a conversa é acumulativa. De outro modo, esse turno pode evidenciar um fazer escolar, expressão utilizada por Jiménez-Aleixandre, Bugallo Rodríguez e Duschl (2000) para referirem-se a práticas cujo objetivo dos alunos é cumprir uma tarefa independente dos conhecimentos que podem ser construídos a partir dela. Nesse caso, o que importa é responder à professora o que é perguntado e não problematizar a pergunta no grupo. No turno 3, a pergunta "por que se amassa a massa do pão" parece desafiar as crianças. Elas se detêm na pergunta e repetem a questão em voz alta mais de uma vez, pois ler e dizer são duas atividades diferentes, porque o dizer não resulta de um conhecimento 'de cor' do texto, mas reflete, por parte de quem expõe o assunto, conhecimento e segurança ao se apresentar (GOULART, 2005).

Percebe-se, nos turnos 5 e 6, elaboração de pensamento, mas as respostas não são vocalizadas. Diante da dificuldade de construção da resposta, no turno 7, Rodrigo 
propõe que cada integrante do grupo elabore uma resposta pessoal e, então por meio de votação, defina-se a resposta do grupo. A interdição de Rodrigo revela o esforço de produção coletiva que é respaldado por Gina. A proposição de escolher e votar em uma resposta vai contra a ordem estabelecida pela professora, mas institui um tempo para que cada criança pense sobre a pergunta e dê sua resposta. Em um curto período, um aluno responde que a massa precisa ficar dura e misturada. No turno 10 , Rodrigo constrói uma suposição, sem elementos de explicação: a massa precisa ser misturada para ficar dura. No turno seguinte, Gisela responde que a massa precisa ser amassada para ficar macia. Verifica-se, nos turnos 10, 11, 13, 14 e 15 a produção de contrapalavras necessárias ao diálogo. É a partir do turno 10 que as crianças oferecem às palavras lidas e ouvidas as suas contrapalavras. Elas aceitam a experiência de leitura do questionário. E as palavras produzidas parecem repetidas porque são recebidas, hospedadas e/ou modificadas. E estas se tornam por sua vez novas contrapalavras, nesse processo contínuo de constituição da singularidade de cada sujeito, pela encarnação da palavra alheia que se torna nossa pelo esquecimento de sua origem (BAKHTIN, 1997).

É importante notar que a partir do turno 7, inicia-se uma conversa competitiva. Assim, observa-se nos turnos 10, 11 e 14 que as respostas de Rodrigo, Gisela e Pedro estão em desacordo. Não há disputa de controle dos enunciados, mas do conteúdo do discurso que se caracteriza por trocas breves, que consistem em afirmações e contraafirmações. A partir do turno 10, a conversa tem como interlocutor Rodrigo, que solicita aos colegas que falem. Ele pensa nas respostas e elege aquela que considera mais pertinente à pergunta. Assim, vemos que Rodrigo assume no grupo o papel social de controlar o fluxo das interações. Dessa forma, sem argumentos de qualquer membro do grupo ou dele próprio, no turno 15, ele acolhe as respostas das outras crianças e, apropriando-se de ideias dos colegas, responde: é preciso amassar a massa do pão para misturar e ficar macia. As perguntas e respostas da questão 3 são apresentadas no quadro 2 que segue.

Quadro 2 - Perguntas e respostas da questão 3

\begin{tabular}{|c|c|c|c|}
\hline $\mathbf{T}$ & Participantes & Discurso & Comentários \\
\hline 18 & Pedro & agora, vamos pra três [...] vamo lá [...] já copiou pergunta e resposta? & \\
\hline 19 & Gina & Já & \\
\hline 20 & Rodrigo & agora, vamo pra três, fio & \\
\hline 21 & Gisela & por que ao se fazer pães é necessário deixar a massa descansar? & Aluna lê para todos \\
\hline 22 & Rodrigo & $\begin{array}{l}\text { por que quando você vai amassar o pão, o pão fica muito cansado [...] ele } \\
\text { trabalhou muito }\end{array}$ & \\
\hline 23 & Alunos & & Risos \\
\hline 24 & Pedro & porque o pão está muito cansado, aí tem de deixar ele no forno & Responde seriamente \\
\hline 25 & Gisela & tem de deixar ele descansando & \\
\hline 26 & Gina & para o pão ficar bem gostoso & \\
\hline 27 & Rodrigo & qual é? [...] é a massa? & $\begin{array}{l}\text { Rodrigo quer saber se estão } \\
\text { falando da massa ou do pão }\end{array}$ \\
\hline 28 & Gisela & e o pão fica bem gostoso & Escreve e repete as palavras \\
\hline 29 & Rodrigo & péra, sô [...] é porque o pão não está pronto ainda & \\
\hline 30 & Gisela & ela não vai no forno? [...] pra massa ou pro pão? pra massa ficar como? & \\
\hline 31 & Rodrigo & é descansando normal ou assando no forno? É assim [...] tipo assim [...] & \\
\hline 32 & Pedro & é tipo assim [...] deixando ela lá & \\
\hline 33 & Gina & porque a massa ainda não está pronta & \\
\hline
\end{tabular}




\begin{tabular}{|l|l|l|l|}
\hline $\mathbf{3 4}$ & Gisela & porque a massa ainda não está fofa & \\
\hline $\mathbf{3 5}$ & Gina & então, descansando no forno, né? & \\
\hline $\mathbf{3 6}$ & Pedro & nó, mas tá difição, hein? dá uma sugestão né? & \\
\hline $\mathbf{3 7}$ & Rodrigo & deixa ele decidir qual das três está melhor [...] a que você falou, a que eu falei [...] & \\
\hline $\mathbf{3 8}$ & Gisela & alá, ele vai falar a minha, quer ver? & \\
\hline $\mathbf{3 9}$ & Pedro & não sei, deixa eu ver, ela falou assim [...] & \\
\hline $\mathbf{4 0}$ & Gina & pra massa ficar bem fofa [...] ela falou assim pra massa ficar mais gostosa & Aponta para Gisela \\
\hline $\mathbf{4 1}$ & Gisela & o pão [...] o pão ficar mais gostoso & \\
\hline $\mathbf{4 2}$ & Rodrigo & $\begin{array}{l}\text { eu falei é pra [...] é porque o pão não está pronto ainda [...] então, é melhor [...] } \\
\text { marca aí, nós já falamos do 'pão ficar bem fofo' ali na primeira, Zé }\end{array}$ & \\
\hline $\mathbf{4 3}$ & Gina & isso é mesmo \\
\hline $\mathbf{4 4}$ & Gisela & não, pra massa ficar bem macia & \\
\hline $\mathbf{4 5}$ & Gina & para a massa \\
\hline $\mathbf{4 6}$ & Pedro & para a massa do pão ficar bem macia & \\
\hline $\mathbf{4 7}$ & Gisela & do pão ficar gostoso \\
\hline $\mathbf{4 8}$ & Rodrigo & então, é a mesma coisa [...] fofo e macio é a mesma coisa [...] então, sei lá [...] & \\
\hline $\mathbf{4 9}$ & Gisela & para o pão ficar gostoso & \\
\hline $\mathbf{5 0}$ & Rodrigo & $\begin{array}{l}\text { tem de deixar ele descansando pra ele respirar ar [...] não, é assim, zé [...] tem } \\
\text { que deixar vir ar no pão [...] fica descansando pra vim ar [...] pro pão [...] pra } \\
\text { ir ar no pão, não é? }\end{array}$ & \\
\hline $\mathbf{5 1}$ & Gina & $\begin{array}{l}\text { pra tipo assim...deixar o pão descansando, aí tipo assim [...] deixando pão } \\
\text { respirando ar [...] vamos escrever isso }\end{array}$ & $\begin{array}{l}\text { Alunos escrevem a resposta no } \\
\text { caderno }\end{array}$ \\
\hline
\end{tabular}

Legenda: [...]: indicação de fala interrompida; ?: interrogação; letras maiúsculas: entoação enfática. Fonte: adaptado de Almeida (2011).

Como é possível verificar, no turno 18 Pedro pergunta se todos copiaram a pergunta e anotaram a resposta da questão anterior, indicando que ele assume a gestão do grupo. E no turno 21, Gisela lê para o grupo: "por que ao se fazer pães é necessário deixar a massa descansar?" E Rodrigo, no turno seguinte responde, brincando com a duplicidade da palavra e as crianças riem. Desse modo, fica evidente que a estrutura formal da língua, por si só, é inadequada para dar conta do sentido do enunciado, conforme indicado por Bakhtin (1997). No turno, 22, o tom jocoso de Rodrigo em relação à palavra é também um questionamento ao pragmatismo do questionário em relação ao uso da linguagem. Dessa maneira, Rodrigo destaca uma outra dimensão da língua - a da variabilidade do sentido de uma mesma palavra de acordo com o contexto em que ela ocorre. Essa dimensão, de acordo com Bakhtin, está, ao mesmo tempo, oculta e evidente no jogo do diálogo.

No turno 24, Pedro responde à pergunta afirmando que o pão precisa descansar no forno. Além do acréscimo à fala do colega, a seriedade da resposta muda o sentido do diálogo. No turno 25, Gisela retoma a palavra descansar da pergunta do questionário e responde, retoricamente, que "tem que deixar ele [o pão] descansando". E no turno 26, Gina completa dizendo que [a massa precisa descansar] para o pão ficar bem gostoso. Nesses turnos, o discurso se caracteriza pelas repetições, confirmações e elaborações mediante a acumulação de ideias.

No turno 27, Rodrigo, na tentativa de responder à pergunta acrescenta outra, cujo sentido é "o que tem que descansar: a massa ou o pão?" A dúvida explicitada pelo aluno traz para o grupo a contraposição dos sentidos gerados pelo uso das palavras. Dessa maneira, a resposta retórica de Gisela, no turno 33, e a de Rodrigo no turno 34, indicam um trabalho de compreensão sobre 'quem' deve descansar - o pão ou a massa; e como deve descansar - ao ar livre ou no forno. As relações estabelecidas 
pelos estudantes evidenciam um processo de produção de sentidos. Tendo em vista a dificuldade de responder à questão, elas produzem sentidos a partir da decomposição da pergunta.

No turno 37, como no episódio anterior, Rodrigo faz uma interdição sugerindo que Pedro escolha a melhor resposta. E, nos turnos seguintes, há uma negociação das palavras para que a resposta seja construída. Em Bakhtin (1997), o sujeito tem um projeto de fala que não depende só de sua intenção, mas depende do 'outro' - o 'outro' com quem fala -; e o 'outro' ideológico, tecido por outros discursos do contexto. $\mathrm{Na}$ tentativa de compreender a pergunta do questionário, as respostas são repetidas em um movimento de especulação. Nesse movimento, fica explícita a dialogização das palavras que são perpassadas pelo discurso alheio. As crianças participam de um diálogo com a pergunta, e também com os seus pares, uma vez que a compreensão não se dá sem que se participe de uma situação de comunicação e, ainda, de outros textos sobre a mesma questão (FIORIN, 2011).

Assim, como se vê nessa sequência, as crianças construíram um diálogo que se caracteriza pelas repetições, confirmações e elaborações. No turno 42, atento ao contexto de produção da linguagem, Rodrigo chama a atenção para o fato de que as respostas ao questionário não poderiam ser coincidentes. Essa observação de Rodrigo caracteriza um fazer escolar (JIMÉNEZ-ALEIXANDRE; BUGALLO RODRÍGUEZ; DUSCHL, 2000). As crianças sabem o que a professora espera delas em relação às respostas do questionário (ALMEIDA; GIORDAN, 2012). E, no turno 50, depois de várias tentativas de ajustes para a resposta, um aluno diz que a massa precisa de descansar para respirar. Mas, Rodrigo não está enunciando um dado do processo de fermentação. A proposição de Rodrigo é uma réplica que se opõe às respostas anteriores. Mas, esse discurso com apreciação especulativa não dialoga com o discurso com entonação científica porque as crianças não explicam o processo, e a resposta é aceita pelo grupo que passa para a questão seguinte. As relações dialógicas nesse fragmento não significam solução de conflitos, embora o conflito esteja instaurado na conversa das crianças. A resposta de Rodrigo é incorporada como a voz de autoridade, possivelmente porque usa de um argumento consistente para convencer seus pares, ou seja: a resposta não pode se repetir. Além disso, ele participa do diálogo de uma forma peculiar: ele pergunta, responde e avalia as respostas das outras crianças na maior parte do fragmento. As respostas das questões 4 e 5 encontram-se no quadro que segue.

Quadro 3 - Perguntas e respostas das questões 4 e 5

\begin{tabular}{|c|c|c|c|}
\hline $\mathbf{T}$ & Participantes & Discurso & Comentários \\
\hline 52 & Rodrigo & quatro [...] vocêjá tinha ouvido falar na palavra fermento? o que ela significa? & Aluno lê outra pergunta \\
\hline 53 & Gisela & eu já ouvi a palavra fermento & \\
\hline 54 & Pedro & EU SEI [...] para encher os bolos [...] é um pó para fazer a massa crescer & \\
\hline 55 & Rodrigo & serve para fazer a massa crescer & \\
\hline 56 & Gisela & NÃO É ISSO NÃO [...] o quê que significa fermento? & \\
\hline 57 & Pedro & para encher o bolo & \\
\hline 58 & Gina & significa para encher o bolo? & \\
\hline 59 & Gisela & $\begin{array}{l}\text { não está perguntando para que serve não, está perguntando o quê significa } \\
\text { [...] tá perguntando o quê a palavra significa [...] o significado da palavra }\end{array}$ & \\
\hline 60 & Rodrigo & então, para que serve? & \\
\hline 61 & Gisela & $\begin{array}{l}\text { AIII!!! NÃO É PARA QUE SERVE! se fosse para que serve [...] a pergunta seria [...] } \\
\text { para que serve? }\end{array}$ & \\
\hline
\end{tabular}




\begin{tabular}{|c|c|c|c|}
\hline 62 & Gina & ah! sei lá [...] vou acabar pulando para a cinco & \\
\hline 63 & Pedro & fazer os ingredientes crescerem & \\
\hline 64 & Rodrigo & NÃO!!! quê fazer os ingredientes crescerem? & \\
\hline 65 & Gina & é mesmo, fazer crescer & \\
\hline 66 & Pedro & fazer massa de bolos, pães & \\
\hline 67 & Gisela & fazer crescer & \\
\hline 68 & Gina & é para fazer crescer & \\
\hline 69 & Rodrigo & não, não é para crescer não gente & \\
\hline 70 & Pedro & é para crescer & \\
\hline 71 & Rodrigo & para [...] vocês concordam? para fazer as massas de pão, bolo, etc [...] crescerem & \\
\hline 72 & Gisela & INGREDIENTES! INGREDIENTES! & \\
\hline 73 & Rodrigo & fazer massa de pão, bolo & \\
\hline 74 & Gisela & ingredientes [...] é para os ingredientes & \\
\hline 75 & Rodrigo & NÃO [...] quê ingredientes? & \\
\hline 76 & Gisela & para fazer os ingredientes da massa crescer & \\
\hline 77 & Pedro & para fazer as massas crescerem & \\
\hline 78 & Gina & os ingredientes & \\
\hline 79 & Rodrigo & $\begin{array}{l}\text { eles estão ouvindo a gente e copiando. Eles estão tirando a resposta da nossa } \\
\text { boca, sô [...] vocês estão ouvindo o da gente [...] ô gente [...] não fala em voz } \\
\text { alta não porque os meninos estão escutando e pegando nossas ideias }\end{array}$ & $\begin{array}{l}\text { Aluno reclama para o seu grupo } \\
\text { que o outro grupo está copiando } \\
\text { as respostas }\end{array}$ \\
\hline 80 & Gisela & $\begin{array}{l}\text { o quê significa [...] vamos ver no dicionário [...][...] uma enzima, um organismo } \\
\text { [...] capaz de provocar a fermentação; levedura }\end{array}$ & $\begin{array}{l}\text { Aluna abre a pasta, tira um dicio- } \\
\text { nário, procura a palavra fermento } \\
\text { e lê em voz alta o significado }\end{array}$ \\
\hline 81 & Gina & então vamos copiar isso aí & \\
\hline 82 & Rodrigo & então, é a mesma coisa [...] fofo e macio é a mesma coisa [...] então, sei lá [...] & \\
\hline 83 & Rodrigo & $\begin{array}{l}\text { cinco [...] dizem que o fermento é o responsável pelo crescimento das massas } \\
{[\ldots . .] \text { como você acha que isso acontece? }}\end{array}$ & Leitura da pergunta \\
\hline 84 & Gisela & por causa da química que tem no fermento & \\
\hline 85 & Pedro & eu acho que ele entra na massa e faz ela esticar & \\
\hline 86 & Rodrigo & ele entra na massa e faz ela esticar por causa da química que tem no fermento & \\
\hline 87 & Gisela & então vamos escrever isso & Alunos copiam a resposta \\
\hline 88 & Gina & pronto, terminamos & \\
\hline
\end{tabular}

Legenda: [...]: indicação de fala interrompida; ?: interrogação; letras maiúsculas: entoação enfática. Fonte: adaptado de Almeida (2011).

Com efeito, no turno 52, Rodrigo lê a pergunta: você já ouviu falar na palavra fermento? O que ela significa? Gisela, no turno 53, diz que já ouvira a palavra, mas não tece nenhum comentário a respeito. No turno 54, Pedro responde aos colegas: "para encher bolos, é um pó para fazer a massa crescer". Ele apresenta a questão central da pergunta - a ação do fermento. Esse aluno, inicialmente, indica para que serve o fermento, no entanto, sua resposta é uma explicação intuitiva à fermentação. No turno 55, Rodrigo compartilha das ideias de Pedro e repete as últimas palavras desse aluno, caracterizando uma conversa acumulativa nesses turnos. No turno 56, Gisela se coloca em desacordo com as ideias de Pedro e Rodrigo. Também fica evidente nesse turno, como a entoação acrescenta algo novo ao próprio ato de fala, algo que é particular ao falante, e implica, portanto, sua singularidade. A entoação é, por assim dizer, testemunha da singularidade da situação dialógica e do particular direcionamento e responsabilidade dos participantes do diálogo. A fala anterior de Gisela remete à palavra dicionarizada. E essa experiência é algo novo que Gisela coloca no seu enunciado e inclui uma instância avaliativa que se expressa no seu tom emocional-volitivo e, por isso, a entoação traz consigo a marca da individualidade sem perder, contudo, sua 
dimensão social. Mas, a justificativa que Gisela elabora não parece clara para as outras crianças. Observa-se, nesse turno, a disputa de Gisela pelo conteúdo e controle da conversa. Ao enfatizar a busca do significado da palavra, ela busca compreensão para as suas ideias. E, Pedro, no turno seguinte, responde à questão da mesma maneira. $A$ partir desse turno, a conversa se desenvolve de maneira mais competitiva. Gina, no turno 58, busca afirmação por meio da pergunta. No turno 59, Gisela retorna à questão explicando o que ela compreendeu da pergunta. A afirmação de Gisela é original e altera os rumos discurso no grupo. A palavra é internamente persuasiva à medida que seu processo de assimilação se dá no entrelace com as palavras dos outros. Esse tipo de acontecimento tem importância fundamental no desenvolvimento da compreensão das perguntas, porque é exatamente essa atitude responsiva, que desperta o motor da significação. Esse movimento discursivo da aluna reafirma sua compreensão ativa por ser mediada por uma pergunta autêntica que expõe suas necessidades e motivos.

A partir desse turno, a polifonia do discurso é instaurada com a distinção entre as expressões "para que serve" e "o quê significa". Para Pedro, Rodrigo e Gina, nos turnos 60, 63, 64 e 68, a questão central da pergunta é a utilidade do fermento. Assim as expressões que as crianças usam para definir o fermento não refletem a ação dos fungos. No entanto, o uso das palavras para explicar o significado da palavra em questão é o início de um longo processo para a compreensão do conceito.

Afinal, percebe-se, nesse fragmento, a preocupação das crianças relativas ao sentido e significado das palavras. Pode-se, nesse caso, trabalhar, também, com a ideia de que as crianças, na interação com o gênero questionário, começam a construir hipóteses sobre a estrutura desse discurso.

Nos turnos 56, 61, 72 e 75 há mudanças de tom na conversa. Observa-se, também, que Gisela, desde o início, marca em suas falas certo desmerecimento pelas falas dos colegas, o que caracteriza a disputa. E, no turno 65, Gina concorda com Pedro e Rodrigo que a função do fermento é para "fazer crescer". Nos turnos 65 e 68, quando as crianças parecem encontrar uma resposta para a ação do fermento, Rodrigo, no turno 68 apresenta uma posição divergente. Mas no turno 71, ele incorpora informações e sugestões apresentadas levando a um entendimento conjunto, característica de uma conversa exploratória. Na sequência, turno 72, Gisela, novamente, se coloca em desacordo com a resposta e o alvo da disputa são as palavras ingrediente e massa. A polifonia e/ou dualidade instaurada nesse episódio poderia ser considerada como uma construção de conhecimento produzido no contexto da interação. Entretanto, a pergunta central sobre a ação do fermento fica em segundo plano, e as crianças, no turno 80 , resolvem a questão com o uso de um dicionário. A busca pelo 'significado' remete a uma exigência escolar de responder conforme o enunciado, ou seja, responder ao que foi solicitado, nada mais. Nos turnos seguintes, as crianças conversam a respeito da química do fermento que faz a massa "esticar". Apesar da resistência às ideias de Gisela e da disputa entre as crianças para a indicação da resposta, a decisão de busca da palavra no dicionário se impõe. Assim, a decisão, inicialmente individualizada de Gisela, é reforçada por outros participantes do grupo.

No turno 79, Rodrigo reclama para o seu grupo que outras crianças estavam ouvindo e copiando a resposta deles, denuncia que "eles estão tirando a resposta da nossa boca". Essa atitude é própria do ambiente escolar. E, desse modo ele indica que 
a conversa precisa ser balbuciada cometendo um ato que viola a liberdade de falar e ser ouvido. O que demonstra que o uso da linguagem implica poder, domínio e regras.

Passado ao turno 83, diante da questão "dizem que o fermento é o responsável pelo crescimento das massas [...] como você acha que isso acontece?", Gisela responde prontamente referindo-se à "química do fermento". Pedro complementa essa ideia afirmando que o fermento faz a massa esticar. Rodrigo, usando as contribuições das falas que o antecederam, reformula a resposta para que todos a transcrevam no caderno. Trata-se, nesse caso, de uma conversa acumulativa, pois a construção de enunciados pelos sujeitos compartilha ideias que se repetem. No turno 86, Rodrigo elabora a resposta, considerando os enunciados anteriores, evidenciando a importância da exposição oral como sendo um dos gêneros que promovem a inserção da criança em contextos mais formais de uso da língua.

\section{Considerações finais}

As questões do questionário aplicado pela professora referem-se ao conceito de fermentação que é estruturador de conhecimentos da química, da física e da biologia. Diz respeito às reações químicas envolvidas na respiração anaeróbica, por meio das quais as células obtêm energia química utilizada em todas as atividades normais e no seu metabolismo. Objeto de estudo retomado em diferentes séries e níveis de ensino de forma cada vez mais complexa. Portanto, é um conceito difícil não só para as crianças. Mesmo que algumas tenham observado o crescimento da massa, a ação dos fungos no interior da massa não está ao alcance dos olhos.

Mesmo que não tenham chegado às respostas cientificamente aceitas, houve aprendizagem relevante para a posterior intervenção da professora, no que se refere ao engajamento na tarefa e na negociação de sentidos para as palavras. O fato de elas terem liberdade de falar, sem antes levantar a mão solicitando à professora autorização e, sem ainda, a intervenção direta da professora faz com que as respostas às questões fossem mais autênticas, ainda que as perguntas orientem um discurso único a ser reproduzido na forma de respostas a serem registradas em cada pergunta.

O corpus analisado mostra que as conversas acumulativas são as mais recorrentes nas interações discursivas do grupo. Esse movimento dialógico de incorporação do já dito é importante porque viabiliza aos falantes e ouvintes o exercício de revisitar o texto escrito e os textos orais, retificar, ampliar, reconstruir o enunciado englobando ideias cada vez mais sofisticadas sobre o tema. Em todo o episódio, há uma reelaboração das ideias, um vai e vem de enunciações demonstrando a necessidade de negociar o sentido das palavras para que elas possam ser compreendidas. Por isso, as conversas acumulativas são importantes para a construção de conhecimentos do grupo investigado, quiçá seja uma marca da oralidade das crianças. As conversas acumulativas são para as crianças um trabalho de ressignificação das palavras dos colegas do grupo.

A análise do episódio evidencia, também, que as crianças quando instigadas a responder o questionário, se apropriam de certos recursos linguísticos caracterizandose, portanto, um exercício de metalinguagem. Trata-se de um trabalho de compreensão realizado por cada criança ao tentar fazer com que sua fala seja mais inteligível. Afinal, é preciso produzir uma resposta ao questionário e, para isso, é necessário fazê-lo de acordo com as convenções da aula, do conteúdo do questionário e de sua forma. 
Assim, a análise detalhada de cada fragmento apresentado (quadros 1 a 3) sugere que a maioria das interações orais foi focada na tarefa de produzir respostas que as crianças acreditavam ser adequadas às expectativas da professora. Contudo, esse esforço impunha às crianças a tarefa de entender as perguntas do questionário e as palavras pronunciadas por cada membro do grupo. Dessa forma, para compreender as perguntas do questionário e as ideias que circularam no grupo foi preciso mais do que uma atitude passiva de entendimento das perguntas, pois as crianças expressavam e ouviam as palavras umas das outras no esforço de construir uma resposta única. É desse esforço de encontrar sentidos na palavra do outro, de reflexão das ideias diferentes que decorre a produção das respostas às perguntas.

É possível observar no quadro 1 que as crianças iniciam a tarefa sem engajamento com as perguntas apresentadas. Elas respondem às questões na tentativa de cumprir a tarefa demandada pela professora. Nesse caso, as interações orais são relativamente breves, superficiais e brandas. A dinâmica discursiva apresenta características de uma conversa acumulativa, mas difere do quadro 2, em que os alunos apresentam maior envolvimento com as perguntas do questionário. Nessa perspectiva, embora o fluxo discursivo apresente características semelhantes à primeira sequência, nota-se, na sequência seguinte, que as crianças ficam mais atentas às perguntas e às repostas, pois o aperfeiçoamento, a diferenciação e o aprimoramento de qualquer conteúdo ocorrem no processo de expressão e de externalização desses conteúdos na interação verbal (SOUZA, 1994).

Por sua vez, o quadro 3 é marcado pela presença de interações discursivas, típicas de conversas acumulativas, competitivas e até exploratórias em alguns enunciados. Talvez, os sentidos dados pelas crianças à pergunta do questionário, e as suas respostas, sejam mais intensos nesse fragmento, dado o fluxo das interações discursivas estabelecido nas sequências anteriores. Além disso, o tipo da pergunta da sequência três pode ter sido um fator determinante para que a maioria das interações se caracterizasse como um misto das categorias citadas neste trabalho. Na sequência três, a qualidade da pergunta abre a possibilidade para uma conversa disputativa, além de indícios de uma conversa exploratória. Nessa sequência, o confronto de ideias é uma oportunidade de reconstrução individual e coletiva dos conhecimentos.

Em alguns momentos, as crianças recorrem à palavra dicionarizada (turno 80), mas é no confronto das falas que elas tomam consciência do que não sabem e explicitam a dificuldade da tarefa. Essa dificuldade gera em alguns o desejo de desistir da pergunta e, em outros, a ampliação e reelaboração da resposta.

Cabe assinalar que a linguagem produzida no grupo não apresenta, com frequência, características de uma conversa exploratória. Embora os falantes compartilhem conhecimentos, o desafio e a avaliação de evidências não estão presentes nesse episódio. Nos anos iniciais, usualmente, a conversa exploratória ocorre na interação professora-crianças, especialmente, em aulas de abertura de uma nova temática.

Chamou a atenção, ainda nesse grupo, o domínio da discussão de algumas crianças. Em algumas ocasiões, alguns membros do grupo ficam subjugados à opinião daqueles que se impõem, e em outras, as crianças mais participativas exigem uma posição dos 
participantes mais quietos. A conversa entre as crianças envolve acordos e desacordos, produtivos e improdutivos. A linguagem como um verdadeiro campo de batalha.

Em última análise, a pesquisa mostrou que as conversas entre as crianças podem contribuir muito para o aprendizado. Entretanto, as atividades que orientaram as conversas precisam ser mais elaboradas pelas professoras. No tocante ao questionário, observou-se que algumas perguntas apresentavam um efeito diferente daquele esperado e, assim, em alguns momentos, o foco das crianças esteve mais a serviço da compreensão das perguntas do que do próprio objetivo da professora. Para ela, as perguntas do questionário seriam geradoras de uma conversa sobre fermentação. Para as crianças, o objetivo era responder às perguntas para a professora.

Há de se destacar que, antes da atividade do questionário, a professora solicitou às crianças receitas de pães, o que as incentivou a conversar, sobretudo, com as mães, sobre o assunto. Esse foi o primeiro movimento realizado pela professora para engajar as crianças no tema a ser estudado. Embora algumas crianças sejam mais articuladas e participativas, como se observou nesse episódio, o que está em jogo não é 'quem sabe mais', mas a elaboração de respostas pelo grupo sobre as concepções acerca de um conceito a ser estudado.

Por fim, conclui-se que, para algumas crianças, a escola pode ser sua única oportunidade real delas de aprender a se envolver em uma discussão focada e fundamentada e, assim, desenvolver habilidades importantes de linguagem e raciocínio. Para isso, é fundamental que a proposta didática apresente diferentes oportunidades de um ensino dialógico; que as crianças sejam estimuladas a pensar, a compartilhar suas ideias e dúvidas com colegas e professora; que as vozes ecoem na sala de aula por sua capacidade de criar um espaço de reciprocidade entre si e o outro.

A cena de abertura deste texto, com a iconografia poderosa de Canetti (1987), representa uma ameaça existencial de castração da linguagem, uma ameaça que é ainda mais poderosa em virtude de que esse acontecimento faz parte de memórias da infância. Resolver essa ameaça, dentro e fora da escola, é "devolver" às crianças o que a elas pertence - a língua efetivamente ligada à sua função de fala!

\section{Agradecimentos}

À Pró-Reitoria de Pesquisa da Universidade Federal de Ouro Preto, pelo financiamento desta pesquisa.

Aos cientistas brasileiros, especialmente, à Professora Guaracira Gouvêa e ao Professor Ângelo Machado pelo trabalho dedicado às crianças.

\section{Referências}

ALMEIDA, S. A. Cenas de leitura da Ciência Hoje das Crianças: modos de uso e apropriação da revista em sala de aula. Educação em Revista, Belo Horizonte, v. 34, p. 1, 2018. DOI: https://doi. org/ggwm7x.

ALMEIDA, S. A. Interações e práticas de letramento mediadas pela revista Ciência Hoje das Crianças em sala de aula. 2011. Tese (Doutorado em Educação) - Faculdade de Educação, Universidade de São Paulo, São Paulo, 2011.

ALMEIDA, S. A; GIORDAN, M. Discursos que circulam na correção de um questionário: sentidos e significados. Ensaio, Belo Horizonte, v. 14, n. 3, p. 239-259, 2012. DOI: https://doi.org/gp33. 
ANDRADE, C. D. Poesia e prosa. Rio de Janeiro: Nova Aguilar, 1988.

BAKHTIN, M. Estética da criação verbal. São Paulo: Martins Fontes, 1997.

BOSCO, S. C. O processo de construção de práticas argumentativas nas aulas de ciências em uma abordagem investigativa: interações discursivas nos anos iniciais do ensino fundamental. 2015. Tese (Doutorado em Educação) - Universidade Federal de Minas Gerais, Belo Horizonte, 2015.

CANDELA, A. Ciencia en el aula: los alumnos entre la argumentacion y el consenso. México: Paidós, 1999.

CANETTI, E. A língua absolvida: história de uma juventude. São Paulo: Companhia das Letras, 1987.

CAPECCHI, M. C. M; CARVALHO, A. M. P. Argumentação em uma aula de conhecimento físico com crianças na faixa de oito a dez anos. Investigações em Ensino de Ciências, Porto Alegre, v. 5, n. 3, p. 171-189, 2000.

CARO, C. M. et al. Construindo consciências: $6^{\circ}$ ano ensino fundamental. São Paulo: Scipione, 2009.

FARACO, C. A. Linguagem e diálogo: as ideias linguísticas do círculo de Bakhtin. Curitiba: Criar Edições, 2003.

FIORIN, J. L. Introdução ao pensamento de Bakhtin. São Paulo: Ática, 2011.

GÓES, M. C. R. A abordagem microgenética na matriz histórico-cultural: uma perspectiva para o estudo da constituição da subjetividade. Cadernos CEDES, Campinas, v. 20, n. 50, p. 9-25, 2000. DOI: https://doi.org/ds8mgj.

GOULART, C. As práticas orais na escola: o seminário como objeto de ensino. Dissertação (Mestrado em Linguística) - Instituto de Estudos da Linguagem, Universidade Estadual de Campinas, Campinas, 2005.

JIMÉNEZ-ALEIXANDRE, M. P.; BUGALLO RODRÍGUEZ, A.; DUSCHL R. A. "Doing the lesson" or "doing science": argument in high school genetics. Science Education, Hoboken, v. 84, n. 6, p. 757-792, 2000. DOI: https://doi.org/bwt8rv.

KRIPKA, R. M. L.; QUADROS, E. L; OLIVEIRA, R. A. P.; RAMOS, M. G. Educação em ciências e matemática: a função da linguagem no contexto da sala de aula. Ensaio, Belo Horizonte, v. 19, p. 1-18, 2017. DOI: https://doi.org/gp36.

MERCER, N. The guided construction of knowledge: talk amongst teachers and learners. Clevedon, England: Multilingual Matters, 1995.

MERCER, N.; HODGKINSON, S. Exploring talk in school. London: Sage, 2008.

MERCER, N.; LITTLETON, K. Dialogue and the development of children's thinking. New York: Routledge, 2007.

PIAGET, J. El criterio moral em el niño. Barcelona: Martínez Roca, 1984.

PIAGET, J. O juízo moral na criança. São Paulo: Summus, 1994..

PIAGET, J. O nascimento da inteligência na criança. Rio de Janeiro: Zahar, 1970.

SOUZA, S. J. Infância e linguagem. Campinas: Papirus, 1994.

TEIXEIRA. F. M. Argumentação nas aulas de ciências para as séries iniciais. In: NASCIMENTO, S. S.; PLATIN, C. Argumentação e ensino de ciências. Curitiba: CRV, 2009. p. 141-164.

VYGOTSKY, L. S. Pensamento e linguagem. São Paulo: Martins Fontes, 1993. 